\title{
Reflexões sobre a intersetorialidade entre as políticas públicas
}

\author{
Reflection about intersecting public policies
}

Sueli do Nascimento*

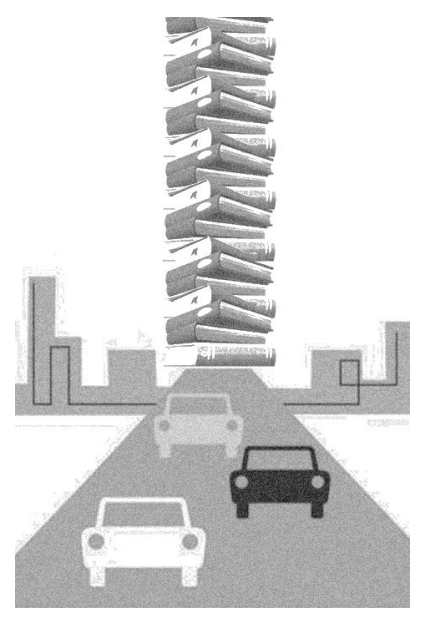

Resumo: O objetivo deste artigo é refletir sobre as possibilidades e limites da intersetorialidade das políticas públicas. Foi utilizada como método de análise a pesquisa documental quando se identificou as políticas com maiores tendências à intersetorialidade.

Palavras-chave: Intersetorialidade. Políticas de desenvolvimento urbano. Política social.

\begin{abstract}
The aim of this paper is to discuss the possibilities and limits of intersecting public policies. The research in documents was used as a method of analysis when the policies with major trends in intersecting were identified.
\end{abstract}

Keywords: Intersecting. Urban development policies. Social policy.

* Professora substituta da Escola de Serviço Social da Universidade Federal Fluminense (UFF), Niterói/ RJ — Brasil. Mestre em Serviço Social e especialista em Política e Planejamento Urbano e Gestão para a Educação Ambiental. E-mail: sucacimento@yahoo.com.br. 


\section{Introdução}

intersetorialidade das políticas públicas passou a ser uma dimensão
valorizada à medida que não se observava a eficiência, a efetivi-
dade e a eficácia esperadas na implementação das políticas setoriais,
primordialmente no que se refere ao atendimento das demandas da população e aos recursos disponibilizados para a execução das mesmas. Deste modo, a intersetorialidade passou a ser um dos requisitos para a implementação das políticas setoriais, visando sua efetividade por meio da articulação entre instituições governamentais e entre essas e a sociedade civil.

A incorporação da intersetorialidade nas políticas públicas trouxe a articulação de saberes técnicos, já que os especialistas em determinada área passaram a integrar agendas coletivas e compartilhar objetivos comuns. Nesta perspectiva, a intersetorialidade pode trazer ganhos para a população, para a organização logística das ações definidas, bem como para a organização das políticas públicas centradas em determinados territórios. Ao mesmo tempo, abrem-se novos problemas e desafios relacionados à superação da fragmentação e à articulação das políticas públicas, sobretudo se considerarmos a cultura clientelista e localista que ainda vigora na administração pública.

Assim, o objetivo deste artigo será refletir sobre as possibilidades e limites para a intersetorialidade das políticas públicas, enfatizando a relação entre as políticas de desenvolvimento urbano e social, bem como as expressões da intersetorialidade presentes nos documentos oficiais das referidas políticas em âmbito nacional, buscando identificar os instrumentos disponíveis para os municípios articularem sua intervenção na cidade.

Neste sentido, o artigo está estruturado em três partes. A primeira apresenta o debate teórico acerca da intersetorialidade, cujo objetivo é identificar a forma como algumas correntes teóricas abordam os avanços, dilemas e desafios para a implementação de políticas públicas incorporando a dimensão intersetorial.

A segunda parte tem por objetivo identificar como a concepção em torno da intersetorialidade se expressa institucionalmente nos documentos oficiais, tomando como referência as políticas urbanas e as políticas sociais. Na terceira 
parte serão tecidas considerações sobre os limites e as possibilidades da intersetorialidade das políticas de desenvolvimento urbano e social.

Com esta análise, buscamos contribuir para o aprofundamento da discussão em torno da intersetorialidade entre as políticas, a fim de aprimorar sua efetividade no atendimento da sua população-alvo, por exemplo, por meio da melhor articulação entre os atores que elaboram, implementam e executam as políticas públicas e na construção de novos mecanismos e experiências que valorizem o saber construído pelos sujeitos envolvidos.

\section{Intersetorialidade: um debate teórico ainda aberto}

Há uma discussão entre as correntes teóricas que tratam da política pública sobre o grau de importância das políticas setoriais, neste caso, as econômicas, sociais e de desenvolvimento urbano. Apesar de não nos aprofundarmos nesta questão, já que o nosso propósito é discutir a intersetorialidade, entendemos que é importante expor alguns apontamentos que possam contribuir com o nosso tema de interesse.

Assim, Koga (2003, p. 223) afirma que há de se constatar o domínio da política econômica sobre a política social, porque o tratamento subalterno dado às políticas no Brasil tem resultado na crescente mercantilização dos serviços tido como básicos à população, quais sejam, os do campo da saúde, da educação ou da habitação, levando a crer num processo de desresponsabilização do Estado.

No que se refere às políticas urbanas, Garson (2007) argumenta que estas se caracterizam pelos compromissos de longo prazo, capacidade fiscal e técnica dos entes federativos, substanciais montantes de recursos desigualmente distribuídos no tempo, incerteza de sucesso e possibilidade de defecções. Já as políticas sociais, sobretudo a partir da década de 1990, recebem recursos definidos e determinados - nos referimos aos conselhos, aos fundos, assim como aos processos administrativos definidos em lei — que garantem maior estabilidade na sua implementação

Por outro lado Ribeiro e Cardoso (2003, p. 109) expõem que a política de investimentos urbanos tem sido orientada, no caso brasileiro, pelos interesses 
do setor econômico, apontando que a agenda de contratação de obras públicas pelo Estado efetivamente tem atendido com maior prioridade aos interesses econômicos específicos das empreiteiras de obras públicas, em detrimento das necessidades da população.

Essas formulações nos levam a considerar que há uma hierarquia de poder no âmbito das políticas públicas em que se destacam as políticas macroeconômicas. Entretanto, dentro da formulação das políticas setoriais também há divergências e interferências econômicas que trazem à tona os interesses e a forma de conduzir tal e qual política conforme os parâmetros daqueles que detêm a decisão final. Observa-se que há um grau de importância atribuída às políticas setoriais, pois atendem à conjuntura e à necessidade dos interesses em jogo, expressas no financiamento de cada uma delas.

Em segundo lugar, devemos focar na análise dos interesses, pois no âmbito das políticas é comum os interesses individuais se sobrepor aos interesses coletivos. Conforme salienta Lobato (2006, p. 304), na formulação de uma política interagem mutuamente interesses diversos, representados por vários setores, entre eles o Estado.

É nesta condição de interesse que emerge o papel dos partidos políticos, dos movimentos sociais, conselhos de direitos e a própria sociedade que elege os seus representantes. Os conflitos são expostos e clarificados ou obscurecidos de acordo com os lobbys realizados pelas partes. Neste aspecto, quando a gestão municipal está submetida ao interesse das elites locais, passa a ser orientada por um único projeto de desenvolvimento. Tal projeto é baseado em dois elementos: "o uso privado dos equipamentos e serviços públicos em proveito próprio e de seus pares e a manutenção de seu eleitorado cativo" (Ramos, 2002, p. 116).

Por fim, é necessário observar como a gestão administrativa nos vários níveis de governo envolvendo todos os entes federados se coloca diante da política pública e da intersetorialidade. Neste aspecto, é preciso considerar tanto os interesses em jogo e os processos de privilegiamento de determinada política setorial quanto as concepções e formatação das políticas pelos diferentes órgãos públicos. Conforme sustenta Junqueira (2004, p. 5), a nova realidade criada a partir de um novo conhecimento deve ser partilhada no interior das 
organizações gestoras das políticas, e isso vai depender da mudança das práticas institucionais e das relações sociais que se estabelecem entre os diversos atores organizacionais e societários. Essas práticas deverão privilegiar a integração de saberes e experiências em prejuízo da setorialização e da autonomização.

Por outro caminho, Silva (2008, p. 90) destaca que é possível vislumbrar novas formas de democratização das relações internas ou do que pode ser chamado "politização" da administração enquanto arte da negociação entre diferentes atores. Para ele o importante é saber se o debate da democratização está na pauta da agenda do Estado e definir o que representa politizar a questão administrativa.

Diante dessas diferentes perspectivas, trazemos para o campo de debate a discussão da articulação entre as políticas de desenvolvimento urbano e social. Para tanto, lançamos mão das contribuições de alguns autores que analisam a articulação entre as políticas e que levam em consideração a questão da segregação territorial, as questões socioterritoriais, lugar, local, espaço, assim como o território. Observa-se que há uma preocupação com a interdisciplinariedade quando se busca discutir a temática da questão urbana e das cidades a fim de abranger outros campos de conhecimento, assim como verifica-se nos artigos do campo das políticas sociais a preocupação com a intersetorialidade.

Entre os autores que chamam a atenção para a dimensão territorial das políticas abordando a questão da intersetorialidade, destaca-se Ribeiro (2007, p. 46), quando menciona que há a necessidade de as intervenções governamentais nas metrópoles buscarem a articulação entre os objetivos da assistência social e a transferência de renda aos grupos mais vulneráveis e os de reconstrução social, habitacional e urbanística dos territórios.

Tanto Koga (2003) quanto Ribeiro (2007) e Sposati (2006) admitem ser o território local privilegiado para realizar a articulação entre as políticas de desenvolvimento urbano e as sociais por considerarem importante a presença dos sujeitos que são alvo das referidas políticas, bem como a valorização desses sujeitos no atendimento aos direitos sociais por eles demandados.

A interface, intersetorialidade, articulação entre as políticas passa então a ser um tema importante para essa pesquisa, já que as políticas setoriais por si só não solucionam tudo e necessitam se comunicar para identificar as necessi- 
dades da população e os benefícios que pode ou não oferecer. Neste sentido, a intersetorialidade na gestão pública significa adotar uma decisão racional no processo de gestão, cuja aplicação pode ser positiva ou não. Ela não pode ser considerada antagônica ou substitutiva da setorialidade, mas complementar, ou seja, deve-se realizar uma combinação entre política setorial com intersetorial, e não contrapô-las no processo de gestão (Sposati, 2006, p. 134).

Para Koga (2003, p. 238), a intersetorialidade sobressai enquanto caminho de perspectiva para a política pública, a fim de articular as políticas sociais, urbanas, econômicas de forma a atuarem nos mesmos territórios prioritários da política da cidade. Isto não significa que suas ações são suficientemente confrontadas e realizadas em um projeto global, que é, naturalmente, pluridisciplinar. A ausência de uma dinâmica pluridimensional significa que os diferentes operadores públicos e associados atuam sobre os serviços que lhes são mais diretamente afetos.

Essa autora advoga que a intersetorialidade se torna, assim, uma qualidade necessária ao processo de intervenção. Programas, projetos, equipes técnicas são desafiados ao diálogo, ao trabalho conjunto com a perspectiva da inclusão social. Neste caso, há de se fazer presente a participação dos membros da comunidade envolvida, enquanto sujeitos do processo da continuidade da proposta (Koga, 2003, p. 242)

A intersetorialidade para Junqueira (2004, p. 4, 9) constitui uma concepção que deve informar uma nova maneira de planejar, executar e controlar a prestação de serviços, de forma a garantir um acesso igual dos desiguais. Isso significa alterar toda a forma de articulação dos diversos segmentos da organização governamental e dos seus interesses. Diante disso, a implantação integrada das várias políticas sociais não depende apenas da vontade política de quem tem o poder ou os recursos disponíveis, pois cada política setorial tem seus interesses e práticas.

Desta forma, realizar um projeto articulado das políticas sociais e desenvolvimento urbano demanda a mudança de práticas, padrões, valores, enfim, da cultura organizacional das instituições públicas gestoras das políticas públicas, ou ainda a incorporação de organizações autônomas voltadas para os interesses coletivos capazes de dar maior eficácia à gestão das políticas. 
Inojosa (2001, p. 4) define a intersetorialidade como a articulação de saberes e experiências para o planejamento, a realização de avaliação de políticas, programas e projetos, cujo fim é alcançar resultados cooperativos em situações complexas. Desta forma, uma perspectiva de trabalho intersetorial implica mais do que justapor ou compor projetos que continuem sendo formulados e realizados setorialmente; de fato, a intersetorialidade traz um conjunto de implicações para a ação do Estado, entre as quais se destacam dois aspectos: (i) os desafios relacionados às polícias focalizadas territorialmente, em segmentos da população; (ii) os desafios relacionados aos resultados e impactos da intervenção.

A intersetorialidade pode ser combinada a modelos ascedentes ou mais descendentes de gestão. Entende-se por ascendente o princípio da intersetorialidade aplicado na base da gestão institucional com setorialidade no modelo de gestão dos órgãos de cúpula, ou seja, a intersetorialidade acontecerá à medida que diferentes representações da gestão municipal se articulam e se integram a fim de atingir uma meta comum e o modelo descendente realiza o movimento contrário, levando em consideração a atuação de diferentes sujeitos/técnicos de organismos públicos e da sociedade civil na formulação de propostas para atendimento comum de uma meta, objetivo etc. (Sposati, 2006).

Sposati, realizando uma análise sobre intersetorialidade, menciona que esta tem dimensões e que precisam ser combinadas, ou seja, a setorial e a intersetorial, como dever do Estado e direito da cidadania. De acordo com ela, o primeiro princípio que rege essa relação parece ser o da convergência, que é um conjunto de impulsos para a ação em determinada situação, seja ela um objeto, um tema, uma necessidade, um território, um grupo, um objetivo, uma perspectiva. Entretanto, considera ser necessário que a intersetorialidade sempre seja corretiva de irracionalidades entre pessoal, funções ou gastos sobrepostos, pois é um mecanismo racionalizador da ação porque é uma estratégia de gestão institucional que busca trazer mais qualidade por permitir ultrapassar limites que ocorreriam na abordagem somente setorial (Sposati, 2006, p. 137).

A intersetorialidade contribui para a criação e reconhecimento de saberes resultante da integração entre as áreas setoriais. Sposati (2006, p. 140) vê a intersetorialidade não só como um campo de aprendizagem dos agentes institucionais, mas também como caminho ou processo estruturador da construção de novas respostas, novas demandas para cada uma das políticas públicas. 
Quando se pensa nas questões negativas que a intersetorialidade pode produzir, Koga (2002, p. 33 e 2003, p. 238) aponta algumas considerações no que se refere aos limites, pois não é a conjugação de várias ações de diferentes secretarias que irá configurar a intersetorialidade, mas uma estratégia comum que a defina; a partir do lugar-comum de ação, quais ou que tipos de intervenção deverão ser efetuadas. E por outro lado, mesmo que as políticas sociais, de desenvolvimento urbano e econômicas atuem nos mesmos territórios prioritários da política da cidade, isto não significa que suas ações sejam confrontadas e realizadas em um projeto global.

De outra forma, Azevedo (2003, p. 41) menciona que a intersetorialidade, para ele interface, diz respeito à inter-relação entre as diversas políticas. Neste contexto, destaca algumas dificuldades para a intersetorialidade no que se refere à crescente especialização do poder público e a tendência de maximização do desempenho de cada um dos órgãos do setor estatal.

Diante disso, há questões para o avanço da gestão da política pública, mas também há as dificuldades que as políticas setoriais possuem no processo intersetorial, isto por conta da própria cultura, dificuldades político-partidárias e outras questões que vão incidir sobre a execução das políticas, já que vão se defrontar interesses e mecanismos lobistas para a sua existência e importância.

Dentro desta perspectiva analítica, passamos aos documentos oficiais, onde poderemos verificar como a intersetorialidade se expressa a fim de garantir que uma política setorial seja executada em articulação com outras. Sabemos que a execução da política pública tem como base os recursos, os arranjos institucionais e os atores, entre outros aspectos, mas aqui vamos focar nossa análise em torno das diretrizes que fundamentam as políticas selecionadas, para entender como os administradores e legisladores públicos federais concebem a intersetorialidade.

\section{Expressões da intersetorialidade nas políticas de desenvolvimento urbano e social}

Apresentamos aqui o resultado da análise dos documentos que sintetizam as diretrizes das políticas urbanas e sociais nacionais, publicadas na forma de 
cadernos do Ministério das Cidades e Assistência Social e Lei n. 8.080/90 de implantação da política de saúde, em que se buscou identificar as concepções em torno da intersetorialidade. Neste aspecto, detemo-nos nas partes que mencionavam a intersetorialidade ou utilizavam sinônimos que pudessem nos levar ao entendimento do significado da atuação intersetorial.

\subsection{Políticas de desenvolvimento urbano}

A partir da criação do Ministério das Cidades, em 2003, a política de desenvolvimento urbano passa a ser assumida como uma questão estratégica pelo governo federal, buscando-se, no seu desenho, a articulação de todas as políticas urbanas. Para expressar essa nova concepção, foram redigidos cadernos para as políticas de: saneamento ambiental, habitação, planejamento territorial urbano e política fundiária e, por fim, mobilidade urbana sustentável, sistematizando a concepção de cada uma dessas políticas, seus principais instrumentos e programas.

Nesta perspectiva, busca-se apresentar as expressões da intersetorialidade em cada uma das políticas, a fim de compreender como aqueles que a elaboraram e a esboçaram por meio dos cadernos refletem sobre a proposta da intersetorialidade, já que é de extrema importância a articulação setorial das políticas em questão, assim como com as sociais, que serão analisadas no próximo item.

A intersetorialidade é mencionada no Caderno da Política Saneamento Ambiental (PNSA), por meio das diretrizes operacionais e organizacionais do processo de implementação da política quando menciona que

a intersetorialidade responde à necessidade de integração das ações de saneamento ambiental entre si e com as demais políticas públicas, em especial, com as de saúde, meio ambiente, recursos hídricos, desenvolvimento urbano e rural, habitação e desenvolvimento regional. (MDS, 2004, p.19)

Pode, também, ser observada algumas palavras que atribuem o mesmo sentido de intersetorialidade como cooperação, ou seja, a "cooperação interinstitucional entre os órgãos da União, dos Estados, do Distrito Federal e dos 
Municípios com o objetivo de elevar a eficácia das ações e explorar as possibilidades de complementariedade" (MDS, 2004, p. 10).

A questão da integração é sobressaltada no sentido de ser criada uma "visão justa e integrada da política ambiental urbana e serem vistos como os fundamentos de uma nova forma de gestão do saneamento ambiental no Brasil" (MDS, 2004, p. 19). Além disto, a relação interministerial e interdisciplinar aparecem na valorização da participação da sociedade e de vários ministérios na elaboração da política nacional de saneamento ambiental. Como afirma o documento,

após ampla participação da sociedade, o MCidades, juntamente com os demais ministérios que compõem o Grupo de Trabalho Interministerial do Saneamento, formulou um ante projeto de lei para a Política Nacional de Saneamento Ambiental que elege o planejamento, a regulação, a fiscalização e controle social como fundamentos para execução das ações de saneamento. (MDS, 2004, p. 9)

Assim, "o Plano Municipal de Saneamento [...] deve estar ancorado em uma metodologia capaz de promover o desenvolvimento interdisciplinar e o das ações, a articulação de diversos órgãos, a participação e controle social" (MDS, 2004, p. 31).

No que se refere a política de habitação, identificamos a intersetorialidade nas diretrizes e princípios dessa política expressas nos Cadernos quando é afirmado que

a implementação da Política Nacional de Habitação implica em um novo desenho político institucional, a partir dos princípios da descentralização, territorialização, intersetorialidade, participação e desenvolvimento institucional e na elaboração e implementação de um Plano Nacional de Habitação. (Min. Cidades, 2006, p. 58)

Além disso, verificamos em todo o texto o emprego das palavras articulação e integração quando da referência de trabalhos com outras políticas setoriais, instituições, setores privados etc. Tal análise pode ser comprovada em um dos itens dos princípios da política que expõe a "articulação das ações de habitação à política urbana de modo integrado com as demais políticas sociais e ambientais" (Min. Cidades, 2006, p. 31); bem como presente em um dos itens dos objetivos gerais de 
tornar a questão habitacional uma prioridade nacional, integrando, articulando e mobilizando os diferentes níveis de governo e fontes, objetivando potencializar a capacidade de investimentos com vistas a viabilizar recursos para a sustentabilidade da PNH. (Min. Cidades, 2006, p. 31)

\section{ou ainda quando menciona a}

atuação integrada com as demais políticas públicas ambientais e sociais para garantir a adequação urbanística e socioambiental das intervenções no enfrentamento da precariedade urbana e da segregação espacial que caracterizam esses assentamentos. (Min. Cidades, 2006, p. 35)

E por fim observamos, também, o uso do termo em conjunto, quando menciona "a promoção, em conjunto com outros órgãos federais e com os demais níveis de governo afetos a questão urbana” (Min. Cidades, 2006, p. 35).

No desenho da política de planejamento territorial urbano e política fundiária, existem quatro linhas de políticas de trabalho, coordenadas pela Secretaria Nacional de Programas Urbanos, que fazem parte da estrutura administrativa do Ministério das Cidades a saber: reabilitação de áreas urbanas centrais, apoio à elaboração e revisão de planos diretores, apoio à regularização fundiária e mobilidade urbana sustentável.

Analisando o referido caderno, foi verificado que nenhuma das quatro políticas menciona a intersetorialidade, mas fazem menções de expressões/ palavras que podem levar à atuação intersetorial, como: estabelecer parceria, trabalho cooperativo, ações integradas, conciliação, promover integração, integração/articulação interministerial.

A primeira política do caderno de planejamento territorial urbano e política fundiária analisada foi a de reabilitação de áreas urbanas centrais, na qual não se observou nenhuma menção que levasse a uma atuação ou intenção para a intersetorialidade, sendo neste caso uma política setorial que tem entre seus objetivos, de cunho social, a geração de emprego e renda e condições habitacionais para as áreas de revitalização, bem como a integração com outras políticas de desenvolvimento urbano e políticas locais.

Já a segunda política — apoio à elaboração e revisão de planos diretores - aponta que a "ação da referida política tem buscado estabelecer parcerias 
com os demais órgãos federais envolvidos no tema, de forma a otimizar os recursos e articular as ações do governo federal" (Min. Cidades, 2004, p. 19).

Em outro trecho está exposta a diretriz de desenvolver "uma prática de trabalho solidário e cooperativo entre Ministério das Cidades, Caixa, municípios e lideranças locais" (Min. Cidades, 2004b, p. 20).

$\mathrm{Na}$ análise da terceira política — apoio à regularização fundiária - foi verificado "que a realidade fundiária apresenta características extremamente preocupantes que exigem ações integradas e contemplem iniciativas diversas" (Min. Cidades, 2004b, p. 44). Por outro lado, nos pressupostos da referida política é observada outra indicação de intersetorialidade, ou seja, a

necessidade de conciliação entre regularização urbanística e ambiental, com a regularização jurídica e patrimonial, bem como aponta que a regularização fundiária tem que ser conciliada com a regularização urbanística e ambiental dos assentamentos com a introdução de programas socioeconômicos e outros programas. (Min. Cidades, 2004b, p. 46-47)

Na quarta política — prevenção de riscos em assentamentos precários —, há menção em um dos trechos do referido documento que

é necessário implementar nos municípios um programa específico de redução de riscos que se articule harmoniozamente e seja complementar aos programas de urbanização integral e regularização fundiária dos assentamentos precários. (Min. Cidades, 2004b, p. 64)

Assim como "compatibilizar as intervenções específicas de redução de riscos com os programas gerais de urbanização e regularização fundiária dos assentamentos precários" (Min. Cidades, 2004b, p. 65).

Por fim, no último caderno, a Política Nacional de Mobilidade Urbana Sustentável — PNMUS — não foi encontrada a expressão intersetorialidade, mas, tal como nas outras políticas analisadas foram observadas expressões que podem levar à atuação intersetorial, como articulação, integração, associação e união. Pode ser apontado, nesta direção, conforme o documento, o conceito de mobilidade que vem sendo construído nas últimas décadas, encontrando "substância na articulação e união de políticas de transporte, circulação acessibilida- 
de e trânsito com a política de desenvolvimento urbano" (Min. Cidades, 2004c, p. 14). No mesmo sentido, foi observado no documento a necessidade de ter garantia de "maior nível de integração e compromisso entre as políticas de transporte, circulação, habitação e uso do solo" (Min. Cidades, 2004c, p. 15).

Constata-se nas diretrizes da PNMUS um item que estabelece com clareza a intencionalidade da intersetorialidade quando expõe a

necessidade de promover e viabilizar associação e coordenação entre a política nacional de mobilidade sustentável e de transporte e trânsito em consonância com as políticas de promoção habitacional, desenvolvimento urbano, meio ambiente e saneamento básico, em especial as de drenagem de águas pluviais e resíduos sólidos. (Min. Cidades, 2004c, p. 52)

Diante das análises apresentadas, surgem algumas questões no que se refere à concepção de intersetorialidade expressa nas palavras e conceitos utilizados no desenho das políticas urbanas a fim de desenvolver uma atuação intersetorial. Percebe-se que, em geral, são utilizadas expressões/palavras no sentido de compreender a intersetorialidade como: integração, articulação, em conjunto, associação, união, entre outras. Mas será que utilizando essas expressões estamos falando em intersetorialidade na implementação da política? Será que essas palavras podem expressar uma proposta intersetorial no plano local? Como garantir a intersetorialidade a partir da proposição de instrumentos administrativos, como diagnósticos, planos e outros? Haverá realmente troca de saberes ou reuniões institucionais para tratar de assuntos momentâneos?

Vale ressaltar que as expressões em muitos dos casos analisados apenas configura uma articulação institucional, interministerial, mas não uma atuação intersetorial que envolva troca de saberes, abranja uma atuação institucional convergente conforme as indicações de Sposati (2006), ainda que observemos a menção de outras políticas. Apenas a política de saneamento ambiental expressa a atuação intersetorial de forma clara e objetiva, expondo articulação com a política de saúde quando da aprovação da redação da política de saneamento no Conselho Federal de Saúde. A política de habitação aponta considerações para a intersetorialidade, interligando-se à questão social no que se refere a uma política de geração de emprego e renda, bem como as considerações de gênero e integração com as políticas de desenvolvimento urbano. 
Vale ressaltar que a política de habitação, apesar de compor a política de desenvolvimento urbano, também deve ser considerada parte das políticas sociais, porque sua intervenção está diretamente vinculada à existência da população e às condições de moradia. É uma das políticas sociais mais custosas, pois edificar uma casa gera gastos elevados para a renda da população empobrecida e moradora de áreas periféricas dos centros urbanos.

A política de planejamento territorial urbano e a política fundiária tratam de questões que podem nos levar à intersetorialidade. Entretanto elas apresentam um desenho eminentemente setorial, tendo em vista que as diretrizes expressas por meio de parceria, integração, ação em conjunto, podem não levar a uma atuação intersetorial que considere a interdisciplinaridade, mas tão somente às disciplinas envolvidas que possam garantir a execução e a implementação da política.

Por fim, cabe mencionar que se observou uma preocupação em articular as referidas políticas setoriais urbanas com a política nacional de desenvolvimento urbano, neste caso, inclusive com a criação do Conselho das Cidades, órgão que conta com a participação da sociedade. Além disto, cabe mencionar a criação de conselhos interministeriais (no caso, vinculado à política de saneamento ambiental), envolvendo a participação de outros ministérios na discussão e implementação dessa política. Por outro lado, observa-se a menção de articulação das políticas de desenvolvimento urbano com as políticas sociais, principalmente aquelas voltadas para geração de emprego e renda, condições de habitabilidade e posse da terra.

Diante das considerações apresentadas é preciso analisar as políticas sociais no que se refere a sua concepção de intersetorialidade e no sentido de verificar se suas ações buscam estar articuladas no sentido de planejar, organizar, otimizar e assegurar a troca de saberes entre setores.

\subsection{Políticas sociais: assistência social e saúde}

As políticas de saúde e assistência social fazem parte do tripé da Seguridade Social no Brasil em que se conjugam com a Previdência Social. Por isso há uma importância política e de democratização no que se refere ao atendi- 
mento das demandas, universalização e garantia de acesso ainda que cada uma delas tenha ações setoriais e necessariamente precisem se articular entre si. Por outro lado, trazem respectivamente como referência a regionalização e o território como expressões de implementação e interface entre as políticas setoriais.

Diante disso, é necessário esclarecer o que é a política social. Para tal, utilizamos as considerações de Behring (1993, p. 17), quando diz que a política social é a síntese de múltiplas determinações, ou seja, por ela passam questões econômicas, políticas, culturais, entre outras, bem como há também uma densidade histórica, pois busca os traços particulares dos processos sociais globais na realidade brasileira. Assim, deve se buscar a decifração da especificidade da formulação sócio-histórica do Brasil em sua relação com esses processos gerais e a configuração específica da política social brasileira.

Vendo a política social como produto dos processos históricos, a política de assistência social na década de 1990 obtém alguns ganhos que traçam a sua estrutura enquanto política pública e direito social com a Constituição Federal de 1988 e com a promulgação da Loas (Lei Orgânica de Assistência Social), desta forma deixando para o passado o cunho assistencialista que a caracterizava, pelo menos do ponto de vista das suas definições formais.

A partir de 2003, a assistência social no Brasil é estruturada administrativamente e passa a ser regida pelo Suas - Sistema Único de Assistência Social —, que tem como referência a Lei Orgânica da Assistência Social, as Nobs Norma Operacional Básicas - e a Constituição de 1988. A gestão proposta para essa política é o pacto federativo, e a forma de enfrentar a questão social foi a descentralização, levando em consideração as desigualdades territoriais e a participação social.

A intersetorialidade passa a ser alvo das discussões no processo de implementação da política de assistência, muitas vezes expressa por meio de palavras que têm sentido similar, como, por exemplo, a interface — conexão —, em que "os serviços de proteção social têm estreita interface com o sistema de garantia de direito, exigindo, muitas vezes, uma gestão mais complexa e compartilhada" (MDS, 2004, p. 31).

Observa-se, ainda, no documento um tratamento da interface enquanto inter-relação, ou seja, "o Plano de Assistência Social expressa a política e suas 
inter-relações com as demais políticas setoriais e com a rede socioassistencial" (MDS, 2004, p. 37).

Em outro ponto, a intersetorialidade é sinônimo de integração, ou seja, "a Política Pública de Assistência Social realiza-se de forma integrada às políticas setoriais" (MDS, 2004, p. 27). Toma o sentido de extravasar, isto é,

nessa vertente, o objeto da ação pública, buscando garantir a qualidade de vida da população, extravasa os recortes setoriais em que tradicionalmente se fragmentam as políticas sociais e em especial a política de assistência social. (MDS, 2004, p. 37)

Verifica-se que a expressão intersetorialidade é marcadamente utilizada quando se refere "à Assistência Social, enquanto política pública que compõe o tripé da Seguridade Social, e considerando as características da população atendida por ela, deve fundamentalmente inserir-se na articulação intersetorial" (MDS, 2004, p. 36).

Os sentidos da intersetorialidade para a política de saúde não é tão expressiva quanto na assistência social, mas na Lei n. 8.080/90 pode-se verificar alguns pontos que legalmente podem apontar o processo intersetorial entre as políticas de saúde e as de meio ambiente e saneamento básico.

O debate sobre a saúde para todos, enquanto direito, remonta às lutas da reforma sanitária no Brasil, o processo de democratização da saúde, do aparelho administrativo e a conquista do SUS — Sistema Único de Saúde. Por mais que haja considerações acerca do avanço e do modelo adotado, como sendo o mais avançado, ainda há problemas a ser enfrentados. Entretanto, a proposta de sistema do SUS é replicada para outras políticas setoriais, como a própria assistência social, habitação dentre outras.

Neste aspecto, as expressões que apontam para uma atuação intersetorial utilizadas na lei que regulamenta a política de saúde dá outro sentido à intersetorialidade, o que poderia ser explicado pelo fato de a Lei n. 8.080, de 1990, ter sido formulada quando o debate da intersetorialidade não tinha tanta expressão, ganhando vulto após esse período.

Neste caso, a palavra articulação pode ser um dos sentidos da intersetorialidade quando a Lei n. 8.080/90, no seu art. $2^{\circ}, \S 1^{\circ}$, menciona que é 
dever do Estado de garantir a saúde consiste na formulação e execução de políticas econômicas e sociais que visem à redução de riscos de doenças e de outros agravos e no estabelecimento de condições que assegurem acesso universal e igualitário às ações e aos serviços para a sua promoção, proteção e recuperação.

Observou-se que a questão da participação pode ser outro sinônimo de intersetorialidade, bem como a palavra colaboração, conforme as ponderações da Lei n. 8.080/90, no art. $6^{\circ}$, quando faz menção "participação na formulação da política e na execução de ações de saneamento básico e a colaboração na proteção do meio ambiente, nele compreendido o da saúde do trabalhador". Tais participação e colaboração, de acordo com o artigo, são campo de atuação do Sistema Único de Saúde.

As diretrizes e os princípios da política de saúde presentes no art. $7^{\circ}$ apontam para a intersetorialidade. Entre os itens mais expressivos, o décimo menciona que deve haver "a integração em nível executivo das ações de saúde, meio ambiente e saneamento básico".

Realizando uma comparação entre as políticas de assistência e saúde, pode-se considerar que elas se complementam, ainda que a saúde não faça menção à política de assistência. As expressões utilizadas para apontar uma atuação integrada também aparecem em ambas as políticas, dando a entender que existe uma propensão à atuação intersetorial.

Para se observar a relação entre as políticas, faz-se necessário ter um olhar mais apurado. Neste sentido, foi proposto no próximo item um quadro analítico de todas as políticas aqui estudadas para verificar a real intersetorialidade entre elas a partir de fatores retirados da literatura. Desta forma, pode se tecer maiores considerações sobre a intersetorialidade.

\section{Considerações finais: limites e possibilidades da intersetorialidade}

As análises sobre a intersetorialidade expressa nas políticas em questão possibilitaram a produção de um quadro analítico que garantiu uma visão ampliada sobre a inter-relação das políticas e, assim, considerar as possibilidades 
e os limites de uma atuação intersetorial em âmbito local, envolvendo gestores e técnicos responsáveis pelo seu desenho e implementação.

Os fatores de análise propostos foram retirados da literatura ou produzidos a partir das leituras e do processo analítico das políticas. Esse processo fortaleceu a proposta de reflexão sobre a intersetorialidade porque pode se verificar como no processo de elaboração se pensa e se constroem propostas que podem incluir ou excluir políticas e incorporar ou se fechar a dimensão intersetorial das mesmas.

Assim, a proposta é ampliar o debate e expor novas possibilidades de encontros entre as políticas, quebrando os limites e referências postas no plano da execução e implementação das políticas em questão. Consideramos importante perceber os entraves que impedem a devida articulação no plano local, já que os documentos analisados são as referências para os municípios e estados na execução das políticas.

Quadro analítico da intersetorialidade entre as políticas de desenvolvimento urbano e social

\begin{tabular}{|c|c|c|c|c|}
\hline Políticas Públicas & Grau & Dimensão & Outras Políticas & Instrumentos \\
\hline $\begin{array}{l}\text { Saneamento } \\
\text { Ambiental }\end{array}$ & $\begin{array}{l}\text { Ascendente/ } \\
\text { Descendente }\end{array}$ & $\begin{array}{l}\text { Setorial/ } \\
\text { Intersetorial }\end{array}$ & $\begin{array}{l}\text { Meio Ambiente, Saúde } \\
\text { Políticas DU }\end{array}$ & $\begin{array}{l}\text { Plano Municipal } \\
\text { de Saneamento } \\
\text { Ambiental }\end{array}$ \\
\hline $\begin{array}{l}\text { Mobilidade Urbana } \\
\text { Sustentável }\end{array}$ & $\begin{array}{l}\text { Ascendente/ } \\
\text { Descendente }\end{array}$ & $\begin{array}{l}\text { Setorial } \\
\text { Intersetorial }\end{array}$ & $\begin{array}{l}\text { Políticas DU } \\
\text { Saneamento Ambiental } \\
\text { Habitação, Meio Ambiente }\end{array}$ & $\begin{array}{l}\text { Plano Diretor } \\
\text { Plano de } \\
\text { Transporte Urbano }\end{array}$ \\
\hline $\begin{array}{l}\text { Política Apoio do } \\
\text { Plano Diretor }\end{array}$ & Ascendente & Setorial & Relação Institucional & Plano Diretor \\
\hline $\begin{array}{l}\text { Política Apoio à } \\
\text { Regularização } \\
\text { Fundiária }\end{array}$ & Ascendente & Setorial & $\begin{array}{l}\text { Meio Ambiente } \\
\text { Habitação } \\
\text { Plano Diretor }\end{array}$ & Plano Diretor \\
\hline $\begin{array}{l}\text { Política de } \\
\text { Reabilitação de } \\
\text { Áreas Urbanas } \\
\text { Centrais }\end{array}$ & Ascendente & Setorial & $\begin{array}{l}\text { Relação Institucional } \\
\text { (Programas de Habitação, } \\
\text { Transporte e Mobilidade } \\
\text { Urbana, Fundiário) }\end{array}$ & $\begin{array}{l}\text { Áreas Urbanas } \\
\text { Centrais }\end{array}$ \\
\hline $\begin{array}{l}\text { Política de } \\
\text { Prevenção de } \\
\text { Riscos em } \\
\text { Assentamentos } \\
\text { Precárias }\end{array}$ & Ascendente & Setorial & $\begin{array}{l}\text { Relação Institucional } \\
\text { (Programas de Regularização } \\
\text { Fundiária e Habitação) }\end{array}$ & $\begin{array}{l}\text { Plano Municipal } \\
\text { de Redução de } \\
\text { Riscos }\end{array}$ \\
\hline
\end{tabular}




\begin{tabular}{|l|l|l|l|l|}
\hline Políticas Públicas & \multicolumn{1}{|c|}{ Grau } & \multicolumn{1}{|c|}{ Dimensão } & \multicolumn{1}{|c|}{ Outras Políticas } & \multicolumn{1}{|c|}{ Instrumentos } \\
\hline Habitação & Ascendente & Setorial & $\begin{array}{l}\text { Saneamento Ambiental } \\
\text { Social } \\
\text { Regularização Fundiária } \\
\text { Políticas de DU } \\
\text { Políticas de Desenvolvimento } \\
\text { Regional e Local }\end{array}$ & $\begin{array}{l}\text { Plano Municipal } \\
\text { de Habitação } \\
\text { Federal, Estadual, } \\
\text { Municipal }\end{array}$ \\
\hline Assistência Social & $\begin{array}{l}\text { Ascendente/ } \\
\text { Descendente }\end{array}$ & $\begin{array}{l}\text { Setorial/ } \\
\text { Intersetorial }\end{array}$ & $\begin{array}{l}\text { Saúde, Educação, Cultura, } \\
\text { Esporte, Emprego, Habitação } \\
\text { e outras. }\end{array}$ & $\begin{array}{l}\text { Planos Municipais } \\
\text { de Assistência } \\
\text { Social }\end{array}$ \\
\hline Saúde & $\begin{array}{l}\text { Ascendente/ } \\
\text { Descendente }\end{array}$ & $\begin{array}{l}\text { Setorial/ } \\
\text { Intersetorial }\end{array}$ & $\begin{array}{l}\text { Saneamento Ambiental, } \\
\text { Meio Ambiente, Educação }\end{array}$ & $\begin{array}{l}\text { Nas comissões } \\
\text { intersetoriais e } \\
\text { outros fóruns }\end{array}$ \\
\hline
\end{tabular}

O grau da intersetorialidade apresentado por Sposati (2006) trata da combinação de modelos ascendentes ou mais descendentes de gestão. Neste caso, o grau ascendente parte da gestão intersetorial de cúpula onde os gestores dos setores se reúnem e compõem agenda e ações com metas únicas, e o descendente parte da gestão da base a partir da participação de sujeitos/técnicos na condução das ações.

Vale mencionar que foram encontradas políticas que se caracterizavam por ascendente e descendente, bem como ascendente/descendente, pois a política da qual se tratava estava sendo pensada ou implementada a partir do grau ascendente e propunha uma relação intersetorial de grau descendente em âmbito local. Em outras políticas, como o Plano Diretor e Regularização Fundiária, verificouse uma relação setorial em que a intersetorialidade não foi proposta e a articulação ficou na esfera dos gestores, a fim de que implementassem os projetos.

No que se refere ao segundo critério, relativo à dimensão, nos remetemos novamente a Sposati (2006), quando expõe que a intersetorialidade apresenta dimensões e que precisam ser combinadas, ou seja, a setorial e a intersetorial, apresentando um princípio que rege essa relação, ou seja, a convergência para um conjunto de impulsos para a ação em determinada situação, um objeto, um tema, uma necessidade, um território, um grupo, um objetivo ou uma perspectiva. Assim, foram identificadas algumas políticas que trazem as dimensões setorial e intersetorial concomitantemente, a saber: saneamento ambiental, mobilidade urbana, saúde e assistência social. 
Analisando o quadro, vemos que a maioria das políticas é ascendente, ou seja, há a intersetorialidade na formulação da política em âmbito federal. Neste caso, busca-se manter articulações com outros setores para a construção das propostas, mas mantém-se a setorialidade no que se refere à organização institucional e administrativa, enquanto para implementação e execução busca-se a articulação com outras políticas.

O quadro apresenta um item denominado "outras políticas", cujo objetivo é expor o número de articulações com outras políticas presentes nos documentos. Neste caso, foram evidenciadas as mais importantes. As relações com as políticas pode ser apenas tanto setorial, para implementar e obter informação, entre outros aspectos, quanto pode ser de planejamento e articulação conjunta, levando a uma atuação intersetorial.

As políticas de regularização fundiária, riscos em assentamentos precários e reabilitação de áreas urbanas centrais não possuem relação direta com outras políticas, mas relações institucionais no âmbito da sua execução e implementação.

Ao analisar a relação entre as políticas, buscamos observar o número de vezes que apareciam no campo "outras políticas". Assim, constata-se que a política de meio ambiente é mencionada pelas de saneamento ambiental, mobilidade urbana sustentável, regularização fundiária e saúde. Neste sentido, tal menção pode expressar o grau de importância e o nível de interesse na referida política para o processo de elaboração e implementação.

A política de saneamento ambiental se articula com a de mobilidade urbana, habitação e saúde, configurando, neste aspecto, a importante tarefa de dirimir os impactos da ausência de saneamento no ambiente, assim como para a saúde da população do país.

A política de habitação se articula com as políticas de mobilidade urbana sustentável, áreas urbanas centrais, prevenção de riscos em assentamentos precários e assistência social, podendo-se visualizar uma correlação das condições habitacionais com as condições urbanas onde se situa a residência e a população nela inserida.

$\mathrm{Na}$ análise da política de saúde, observou-se que ela se relaciona com as políticas de saneamento ambiental e assistência social. É considerada de extre- 
ma importância a relação dessa política com a habitação, já que as condições de saúde de um morador também está relacionada às condições de habitação, ou melhor, de moradia, que abrange todas as demais políticas do quadro. No entanto, apesar dessa importante articulação, ela não é citada pela política de habitação.

O interessante no campo de análise é observar que todas as políticas relacionadas ao desenvolvimento urbano se interagem. Foi constatado nos documentos analisados que há espaços de reuniões interministerial, conselho e outros que favorecem essa integração. Entretanto, não se observou a manutenção dessa mesma relação com alguns espaços das políticas sociais, exceto a política de saneamento ambiental por meio de Conselho de Saúde.

A habitação e apoio à área de reabilitação de assentamentos precários apontaram em seus documentos de referência a relação e a preocupação com as políticas de desenvolvimento regional e local a fim de atender as especificidades regionais e locais de implementação das políticas em questão, o que não se verificou nos demais documentos.

A análise do quadro suscita questões no que se refere à política de assistência, que não são mencionadas por nenhuma das outras políticas para atuação intersetorial. Foi verificado nos documentos das políticas de habitação, áreas de reabilitação, saneamento ambiental, que se considera importante as condições de vida da população no que se refere a geração de emprego e renda, posse da terra e a relação de propriedade, a dimensão de gênero, mas sem o propósito de uma atuação intersetorial com a política de assistência social.

Desta forma, questiona-se o porquê da ausência de tal relação. O que os elaboradores das políticas entendem sobre a política de assistência? Por que a assistência não é vista como uma política importante a ser articulada na implementação das demais políticas? Tais questões inquietam, no sentido de procurar compreender os motivos de tal anulação dessa política, já que ela atende ao mesmo público das demais políticas em voga, ou seja, a população empobrecida e os residentes de áreas precárias.

Trazer essa análise para o centro de discussão é necessário na medida que os objetivos das políticas em questão é atender uma população afastada dos benefícios da mobilidade urbana, das condições de habitabilidade e de saúde, 
bem como de saneamento ambiental e social, neste caso envolvidas nas políticas de desenvolvimento urbano.

Sposati (2006) menciona a importância da intersetorialidade, mas sem anular a setorialidade. Aqui pode ser observado que a setorialidade pode anular a intersetorialidade dependendo das concepções e diretrizes que informam as políticas, sobretudo a da assistência social, e de como ela é considerada pelas políticas de desenvolvimento urbano. Assim, questiona-se: como os elaboradores das políticas de desenvolvimento urbano compreendem e veem a política de assistência social?

Na lei que implanta o SUS foi observado que não havia planos, mas mencionavam-se comissões intersetoriais que podem expressar a intersetorialidade, já que a própria política de saúde traz no corpo da lei a relação com a política de meio ambiente e saneamento ambiental.

Consideramos importante observar que contemporaneamente a organização administrativa do SUS sofreu modificações no que se refere à participação de outras políticas setoriais no processo de discussão de política de saúde, já que ela é datada de 1990, decorridos, portanto, dezenove anos da sua formulação. Como não nos detivemos nas Normas Operativas da Saúde para verificar como se apresentava a intersetorialidade, é necessário considerar a possibilidade de estar acontecendo a intersetorialidade nas esferas administrativas e, principalmente, em âmbito local no decorrer desses anos.

No campo dos instrumentos, vale ressaltar que a política de assistência expressa, no documento analisado, a importância de a intersetorialidade se exprimir no âmbito local por meio do Plano Municipal de Assistência Social, mas nas outras políticas não encontramos a concretização operacional da intersetorialidade, e ficou subentendido tal importância. Por isso, em algumas das políticas apresentadas foi verificada a necessidade de produzir planos locais, não só para expressar a intersetorialidade, mas organizar e planejar as ações de cada política.

O Plano Diretor também foi um instrumento mencionado onde poderia se apresentar a intersetorialidade, principalmente em algumas das políticas de desenvolvimento urbano. Ressalta-se, neste sentido, por que o Plano Diretor também não é considerado uma referência para todas as políticas pesquisadas, 
tendo a necessidade criar planos específicos para cada política. Considera-se importante que haja um planejamento setorial, mas sem perder de vista a necessidade de comunicação entre os setores e, sobretudo, considerando a cidade (município) lócus privilegiado de execução da política pública e da intersetorialidade, bem como da participação e do controle social.

O Plano Diretor é um dos instrumentos de gestão de uma cidade. Refletindo sobre o seu papel, podemos formular a questão: como pensar a cidade com um plano global sem fragmentar o olhar sobre a mesma por meio de tantos outros planos setoriais? Considerando que os planos das políticas em questão atendem a população de um território, vivendo em determinadas condições sociais, podemos indagar se há interação entre os planos apontados com o Plano Diretor da cidade?

As análises dos documentos nos auxiliaram a compreender as possibilidades e os limites das referidas políticas no plano teórico e reflexivo apresentados nos cadernos analisados. Constata-se que para haver uma real intersetorialidade é necessário construir espaços com tais objetivos comuns que possibilitem a comunicação entre as políticas sociais com as de desenvolvimento urbano, no que se refere à troca de saberes, interações no processo de elaboração, formulação e execução da política, bem como com a disponibilidade dos técnicos e gestores das pastas das referidas políticas no processo de planejamento concomitantemente apoio político.

O saber de determinada política setorial é importante, mas também expõe a necessidade de troca a fim de possibilitar a construção de novos saberes. Neste caso, a interdisciplinaridade ganha força quando os saberes técnicos conseguem sair da sua pasta de origem e cunhar possibilidades de construção de uma política inclusiva e articulada às reais necessidades da população.

Assim, este artigo teve a intenção de refletir sobre a intersetorialidade a partir de uma análise documental, por isso restrita, o que coloca como necessidade a ampliação da análise para o plano da implementação concreta das políticas nos municípios, Distrito Federal e estados.

Neste aspecto, é por meio da realidade cotidiana que se pode conseguir vislumbrar possibilidades e limites para a intersetorialidade, pois o processo reflexivo é anterior à prática, mas se articula o tempo todo para a construção de 
novas visões e interações. Aqui, tais visões e interações foram colocadas sobre as políticas de desenvolvimento urbano e social na forma documental.

Tanto as políticas de desenvolvimento urbano quanto a social trazem em seu bojo algumas perspectivas de ações intersetoriais, podendo fortalecer as atuações dos gestores e técnicos, a articulação com a população local, dar base para a interação de saberes (interdisciplinaridade) ou criação de outros, promover e consolidar ações políticas e trabalhar com a logística do processo de implementação.

Por outro lado, os interesses dos sujeitos envolvidos também passam a ser um divisor de águas, na medida em que estes podem ser obscurecidos, e as ações intersetoriais podem tanto estar voltadas para respostas imediatas, como podem se reverter em ações contundentes que consigam criar barreiras políticas de enfrentamento aos interesses.

Assim, buscou-se mostrar que as políticas se comunicam de forma restrita, mas questionou-se a qualidade desta interação, e o que limita tal interação no plano local só pode ser demonstrado com novas pesquisas e análises. Por isso, este artigo propõe e incentiva a reflexão sobre a intersetorialidade, expondo que no plano analítico das políticas em questão existem bases importantes a partir das quais é possível construir a intersetorialidade

Artigo recebido em nov./2009 - Aprovado em jan./2010

\section{Referências bibliográficas}

AZEVEDO, Sérgio. Políticas públicas: discutindo modelos e alguns problemas de implementação. In. Políticas públicas e gestão local: programa interdisciplinar de capacitação de conselheiros municipais. Rio de Janeiro: Fase, 2003. p. 38-44.

BEHRING, Elaine Rossetti. A nova condição da política social. Em Pauta. Rio de Janeiro, n. 10, p. 9-49, nov. 1993.

BRONZO, Carla; VEIGA, Laura da. Intersetorialidade e políticas de superação da pobreza: desafios para a prática. Serviço Social \& Sociedade, São Paulo, n. 92, p. 5-21, nov. 2007. 
CKAGNAZAROFF, Ivan Beck; MELO, Joyce de Souza Cunha; CARVALHO, Débora Nacif de. Da gestão da intersetorialidade: o caso do Programa BH Cidadania, Brasil. Anais do Congreso Internacional del CLAD sobre la Reforma del Estado y de la Administración Pública. Santiago, Chile, p. 18-21, oct. 2005.

GARSON, Sol. Regiões Metropolitanas: obstáculos institucionais à cooperação em políticas urbanas. Tese (Doutorado). Instituto de Pesquisas e Planejamento Urbano e Regional — Universidade Federal do Rio de Janeiro. Rio de Janeiro, 2007. p. 64-104 e 130-182.

INOJOSA, Rose Marie. Intersetorialidade e a configuração de um novo paradigma organizacional. RAP, Rio de Janeiro, n. 32, p. 35-48, mar./abr. 1998.

Sinergia em políticas e serviços públicos: desenvolvimento social com intersetorialidade. Cadernos Fundap, São Paulo, n. 22, p. 102-110, 2001.

JUNQUEIRA, Luciano A. Prates. A gestão intersetorial das políticas sociais e o terceiro setor. Saúde e Sociedade, São Paulo, v. 13, n. 1, p. 25-36, jan./abr. 2004.

Descentralização e intersetorialidade: a construção de um modelo de gestão municipal. RAP, Rio de Janeiro, n. 32, p. 11-22, mar./abr. 1998.

; INOJOSA, Rose Marie; KOMATSU, Suely. Descentralização e intersetorialidade na gestão pública municipal no Brasil: a experiência de Fortaleza. Anais do XI Concurso de Ensayos del Clad "El Tránsito de la Cultura Burocrática al Modelo de la Gerencia Pública: Perspectivas, Posibilidades y Limitaciones”. Caracas, 1997.

KOGA, Dirce. Cidades entre territórios de vida e territórios vivido. Serviço Social \& Sociedade. São Paulo, n. 72, p. 23-52, nov. 2002.

. Medidas de cidades entre territórios de vida e territórios vividos. São Paulo: Cortez, 2003.

LOBATO, Lenaura V. S. Algumas representações sobre a representação de interesses no processo de formulação de políticas públicas. In: Políticas Públicas. Coletânea. Brasília: Enap, 2006, v. 2, p. 289-311.

MENICUCCI, Telma Maria Gonçalves. Intersetorialidade, o desafio atual para as políticas sociais. Pensar BH/Política Social. Belo Horizonte, p. 10-13, maio/jul. 2002. MINISTÉRIO DAS CIDADES. Caderno de Saneamento Ambiental 5. Brasília, out. 2004a.

Caderno de Planejamento Territorial Urbano e Política Fundiária 3. Brasília, nov. 2004b. 
MINISTÉRIO DAS CIDADES. Caderno de Política Nacional de Mobilidade Urbana Sustentável 6. Brasília, nov. 2004c.

Caderno de Habitação 4. Brasília, maio 2006.

MINISTÉRIO DO DESENVOLVIMENTO SOCIAL E COMBATE À FOME — MDS. Política Nacional de Assistência Social. Brasília, nov. 2004.

RAMOS, M. H. R.; BARBOSA, M. J. S. Gestão de políticas urbanas e mecanismos de democracia direta. In: Metamorfoses sociais e políticas urbanas. Rio de Janeiro: DP\&A, 2002. p.113-131.

RIBEIRO, Luiz Cezar de Queiroz. Metrópoles, reforma urbana e desenvolvimento nacional. In: . As metrópoles e a questão social brasileira. Rio de Janeiro: Reven, 2007. p. 21-50.

; CARDOSO, Adauto Lucio. Plano diretor e gestão democrática da cidade. In: Reforma urbana e gestão democrática: promessas e desafios do Estatuto da Cidade. Rio de Janeiro: Revan, 2003. p. 103-118.

SILVA, Gustavo Tavares da. Políticas públicas e intersetorialidade: uma discussão sobre a democratização do Estado. Cadernos Metrópole n. 19, p. 81-97, $1^{\text {o }}$ sem. 2008.

SPOSATI, Aldaíza. Gestão pública intersetorial: sim ou não? Comentários de experiência. Serviço Social \& Sociedade, São Paulo, n. 85, p. 133-141, mar. 2006.

VIANNA, Ana Luiza D'Ávila. Novos riscos, a cidade e a intersetorialidade das políticas públicas. RAP, Rio de Janeiro, n. 32, p. 3-33, mar./abr. 1998. 